functioning $(61.1 \pm 24.9$ versus $55.0 \pm 26.5 ; \quad P<0.001)$, role physical (53.2 \pm 26.9 versus $50.3 \pm 27.7 ; P=0.036)$, bodily pain $(49.5 \pm 23.8$ versus $47.1 \pm 25.3 ; P=0.016)$, FACIT-Fatigue scores $(30.5 \pm 11.8$ versus $29.3 \pm 11.9 ; P=0.046), E Q-5 D$ scores $(0.75 \pm 0.18$ versus $0.72 \pm 0.19$; $P=0.004)$ and $E Q-5 D$ visual analogue scale (VAS) scores (64.6 \pm 19.4 versus $61.7 \pm 18.6 ; P=0.001)$. The difference in SF-36 physical functioning was the greatest one among the SF-36 parameters, exceeding the corresponding MCID ( $\geq 5.0$ points). The association between AMA use and better physical functioning was still significant after adjustment for potential confounding factors (standardised coefficient, $\beta=0.08 ; P=0.001$ ). In this analysis, Asian patients performed better in physical functioning $(\beta=0.07 ; P=0.004)$ while African/African American patients performed worse $(\beta=-0.07 ; \quad P=0.003)$. High disease activity $(\beta=-0.09 ; \quad P<0.001)$ and organ damage $(\beta=-0.12 ; P<0.001)$ were also independent factors of worse physical functioning, whereas corticosteroid use independently improved the outcome $(\beta=0.06 ; P=0.022)$.

Conclusion: AMA use contributes to better physical functioning in patients with SLE, independently of other factors.

Acknowledgement: The authors would like to thank GlaxoSmithKline (Uxbridge, UK) for granting access to the data from the BLISS-52 and BLISS-76 trials (ClinicalTrials.gov identifiers NCT00424476 and NCT00410384, respectively) through the Clinical Study Data Request (CSDR) consortium.

Disclosure of Interests: None declared

DOI: 10.1136/annrheumdis-2019-eular.6430

\section{FRI0206 HYDROXYCHLOROQUINE BLOOD LEVELS PREDICT RETINOPATHY IN SLE}

Michelle A. Petri ${ }^{1}$, LI Jessica ${ }^{1}$, Marwa Elkhalifa², Daniel Goldman ${ }^{1}$,

Laurence Magder'. ' Johns Hopkins University School of Medicine, Rheumatology, Baltimore, United States of America; ${ }^{2}$ Alexandria University, Medicine, Alexandria, Egypt, ${ }^{3}$ University of Maryland, Epidemiology and Public Health, Baltimore, United States of America

Background: Hydroxychloroquine (HCQ) retinopathy after 10 years or more of use is more frequent than previously appreciated. This led to new ophthalmology guidelines that changed the recommended dosing from $6.5 \mathrm{mg} / \mathrm{kg}$ to $5 \mathrm{mg} / \mathrm{kg}(1)$. However, it is not clear that the lower dose of hydroxychloroquine will have the same efficacy for SLE activity or the same protective role against cardiovascular risk factors and thrombosis.

Table 1. Risk of $\mathrm{HCQ}$ retinal toxicity (univariate)

\begin{tabular}{|c|c|c|c|c|}
\hline & No & Yes & & \\
\hline Characteristic & n (\%) & $\mathrm{n}(\%)$ & $p$ & $\begin{array}{l}\mathrm{P} \text { for } \\
\text { Trend }\end{array}$ \\
\hline Sex & & & 0.1029 & \\
\hline Female & 475 (96.2) & $19(3.8)$ & & \\
\hline Male & $39(90.7)$ & $4(9.3)$ & & \\
\hline Ethnicity & & & 0.3804 & \\
\hline White & $238(94.4)$ & $14(5.6)$ & & \\
\hline Black & 215 (96.4) & $8(3.6)$ & & \\
\hline Other & $61(98.4)$ & $1(1.6)$ & & \\
\hline Age & & & $<0.0001$ & $<0.0001$ \\
\hline$<45$ & 215 (99.5) & $1(0.5)$ & & \\
\hline $45-59$ & 175 (95.6) & $8(4.4)$ & & \\
\hline $60+$ & $124(89.9)$ & $\begin{array}{c}14 \\
(10.1)\end{array}$ & & \\
\hline $\mathrm{HCQ} \max$ & & & 0.0340 & 0.0143 \\
\hline 1 (0 to 1182$)$ & $161(98.8)$ & $2(1.2)$ & & \\
\hline $\begin{array}{l}2(1183 \text { to } \\
1752)\end{array}$ & 157 (95.2) & $8(4.8)$ & & \\
\hline $\begin{array}{l}3(1753 \text { to } \\
6281)\end{array}$ & 153 (93.3) & $11(6.7)$ & & \\
\hline $\mathrm{HCQ}$ duration & & & 0.0006 & 0.0002 \\
\hline 1 (0 to $8 y r s)$ & $158(98.8)$ & $2(1.2)$ & & \\
\hline 2 (9 to $15 y r s)$ & 139 (97.2) & $4(2.8)$ & & \\
\hline 3 (16 to $48 y r s)$ & $154(90.1)$ & $17(9.9)$ & & \\
\hline BMI & & & 0.1701 & 0.0160 \\
\hline$<20$ & $50(98.0)$ & $1(2.0)$ & & \\
\hline $20-25$ & $171(97.7)$ & $4(2.3)$ & & \\
\hline $25-30$ & 159 (95.2) & $8(4.8)$ & & \\
\hline $30-35$ & $76(95.0)$ & $4(5.0)$ & & \\
\hline $35+$ & $58(90.6)$ & $6(9.4)$ & & \\
\hline HTN Ever & & & 0.0020 & \\
\hline Yes & 276 (93.2) & $20(6.8)$ & & \\
\hline No & 238 (98.8) & $3(1.2)$ & & \\
\hline
\end{tabular}

identify those at greater future risk of retinopathy.
Methods: We analyzed data on 537 SLE patients from a clinical cohort who had repeated assessments of $\mathrm{HCQ}$ blood concentrations, and were evaluated one or more times for retinopathy (300 single retinopathy exam, 149 two and 88 three or more assessments). The patients were $92 \%$ female and $42 \%$ Caucasian. Hydroxychloroquine blood levels were performed as previously described. In our analysis, HCQ toxicity was defined dichotomously by a retina expert: all those with a value of "No" or "Possible" were categorized as not having HCQ toxicity, and those who had a "Yes" were categorized as having it. Mean and maximum $\mathrm{HCQ}$ blood concentration over all cohort visits prior to the final retinop athy assessment were calculated. Risk of $\mathrm{HCQ}$ toxicity was then assessed in tertiles defined by these variables.

Results:

Conclusion: Our data show that the risk of $\mathrm{HCQ}$ retinopathy is higher in men and Caucasians. As expected, it is higher in older patients and with greater duration. We also found that BMI and hypertension were predictive of $\mathrm{HCQ}$ retinopathy. For the first time, our data show the utility of HCQ blood levels in predicting retinopathy. This would allow clinicians to either decrease dose or increase monitoring in those with high blood levels.

\section{REFERENCES :}

[1] Marmor MF, Kellner U, Lai TYY, Melles RB, Mieler WF. Recommendations on screening for chloroquine and hydroxychloroquine retinopathy (2016 revision). Ophthalmology 2016;123:1386-1394.

Acknowledgement: The Hopkins Lupus Cohort was funded by NIH Grant R01-AR069572

Disclosure of Interests: Michelle A Petri Shareholder of: Pfizer, Merck Grant/research support from: AstraZeneca, Exagen, Consultant for: Eli Lilly, GSK, Merck EMD Serono, Janssen, Amgen, Novartis,

Quintiles, Exagen, Inova Diagnostics, AstraZeneca, Blackrock,

Glenmark, UCB, and the Annenberg Center for Health Sciences, Jessica Li: None declared, Marwa Elkhalifa: None declared, Daniel Goldman Shareholder of: Pfizer, Merck, Laurence Magder: None declared DOI: 10.1136/annrheumdis-2019-eular.7516

\section{FRI0207 BASELINE LEVELS OF BAFF, APRIL AND CD8+ EFFECTOR MEMORY CELLS AS PREDICTORS OF SLEDAI RESPONSE TO BELIMUMAB THERAPY}

Francesca Regola ${ }^{1}$, Silvia Piantoni ${ }^{1}$, Laura Andreoli ${ }^{1}$, Torsten Lowin ${ }^{2}$, Rajesh Kumar ${ }^{1}$, Paolo Airò ${ }^{1}$, Franco Franceschini ${ }^{1}$, Angela Tincani ${ }^{1}$, Georg Pongratz ${ }^{2} .{ }^{1}$ U.O. Rheumatology and Clinical Immunology, ASST Spedali Civili of Brescia, Department of Clinical and Experimental Sciences, Brescia, Italy; ${ }^{2}$ University Hospital Düsseldorf, Department of Rheumatology and Hiller Research Center for Rheumatology, Düsseldorf, Germany

Background: Systemic lupus erythematosus (SLE) patients show high circulating levels of BLyS (B lymphocyte stimulator, also known as BAFF and of other cytokines belonging to the tumor necrosis factor (TNF) superfamily [1]. Belimumab is a monoclonal antibody against soluble BLyS used for treatment of refractory SLE. Although B cells are the main target of this therapy, a BLyS-dependent $T$ cell activation pathway has also been demonstrated [2]. Clinical studies showed that high levels of anti-DNA antibodies and low complement at baseline are predictors of response to Belimumab treatment.

Objectives: Our study aims at exploring the role of biomarkers belonging to the TNF superfamily and of effector T-lymphocytes as predictors of response.

Methods: Twenty-one patients with SLE received Belimumab. Clinical evaluation and laboratory test were performed at baseline and after six and twenty months of therapy. Biomarkers belonging to the TNF superfamily (BAFF, APRIL, SBCMA, sCD40L, sTACI, TWEAK) were tested by high-sensitivity ELISA in all patients and lymphocyte immunophenotyping was performed by flow cytometry in ten subjects. SLE-disease activity was assessed by SLEDAI-2K score.

Results: BAFF and APRIL baseline serum levels and the number of CD3 + CD8+ effector memory $T$ cells were correlated positively with SLEDAI-2K improvement after 12 months of treatment (Pearson correlation $=0.535$ $(p=0.015), 0.504(p=0.023)$ and $0.654(p=0.040))$. After backwards exclusion from linear regression analysis including SLEDAI-2K, effector $T$ cell relative number and BAFF or APRIL at baseline, only APRIL remained as significant independent predictor of SLEDAI-2K improvement after 12 months of therapy (adjusted $\mathrm{R}$ square $=0.649$; $\mathrm{p}=0.025$ ). Moreover, after comparing TNF-family members serum levels and SLEDAI-2K at baseline, only BAFF showed the best predictive value (adjusted $R 0.564, p<0.001$ ). 